\title{
Non-enzymatic kinetic resolution of 3-hydroxyalkanamides with chiral copper catalyst
}

\author{
Yosuke Demizu, Yuki Kubo, Yoshihiro Matsumura, Osamu Onomura* \\ "Graduate School of Biomedical Sciences, Nagasaki University, 1-14 Bunkyo-machi, Nagasaki 852-8521, Japan”
}

Fax: +81-95-819-2476

E-mail: onomura@nagasaki-u.ac.jp

Received: The date will be inserted once the manuscript is accepted.

Abstract: Kinetic resolution of 3-hydroxyalkanamides with good to high selectivities was achieved by benzoylation using copper(II) triflate and $(R, R)$-Ph-BOX as a catalyst, which also mediated enantioselective tosylation of 2,2bis(hydroxymethy)alkanamides with high efficiency.

Key words: Kinetic resolution, 3-Hydroxyalkanamides, Acylations, Chiral copper complex, Molecular recognition

Optically active 3-hydroxyalkanoic acid derivatives are important precursors for preparations of various biologically active compounds. ${ }^{1}$ A variety of enzymatic kinetic resolution methods has been developed for preparation of optically pure 3-hydroxyalkanoic acid derivatives. ${ }^{2}$ To the best of our knowledge, nonenzymatic method has been little known to date. ${ }^{3} \mathrm{Re}$ cently, we have reported an efficient method for kinetic resolution of 1,2-diols 1 . The method is based on recognition of 1 by copper ion associated with chiral ligand $(R, R)-\mathrm{Ph}-\mathrm{BOX}^{4}$ to afford the activated intermediates 2 followed by benzoylation (Scheme 1$).^{5}$

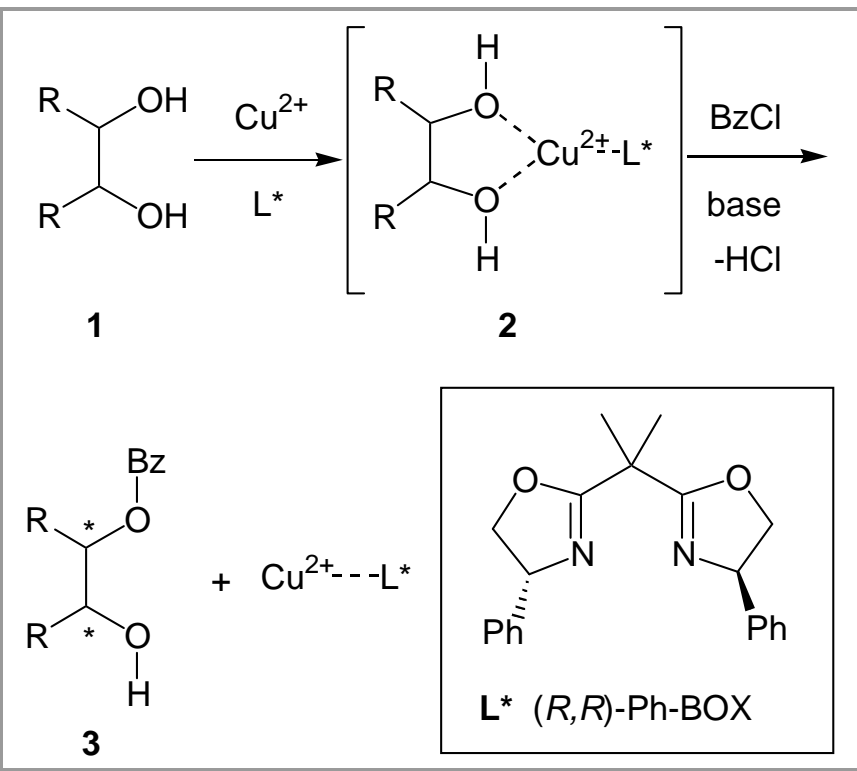

Scheme 1 Asymmetric benzoylation of 1,2-diols 1 based on the recognition by $\mathrm{Cu}(\mathrm{II})-(R, R)-\mathrm{Ph}-\mathrm{BOX}$

We report herein non-enzymatic kinetic resolution of 3hydroxyalkanamides by benzoylation with $\mathrm{Cu}(\mathrm{II})-(R, R)-\mathrm{Ph}-\mathrm{BOX}$ catalyst affording optically active 3-hydroxyalkanamide derivatives in good to high yields and enantioselectivities.
We began our investigation by trying benzoylation of ethyl DL-3-hydroxybutanoate (4) as a model compound to see whether it could be recognized by chiral copper(II) complex or not. We found out the following, in the absence of copper(II) triflate and $(R, R)-\mathrm{Ph}-\mathrm{BOX}$ the reaction of 4 with $\mathrm{BzCl}$ did not almost proceed, while in the presence of the catalysts, benzoylated product 5 was obtained in 19\% yield based on 4. In contrast, DL-3hydroxy- $N$-phenylbutanamide (6a) was benzoylated more efficiently in the presence of $\mathrm{Cu}(\mathrm{II})-(R, R)-\mathrm{Ph}-$ BOX to afford benzoylated product $7 \mathbf{a}$ in $41 \%$ yield (Scheme 2). These results imply that 6a was efficiently recognized by $\mathrm{Cu}(\mathrm{II})-(R, R)-\mathrm{Ph}-\mathrm{BOX}$ complex.

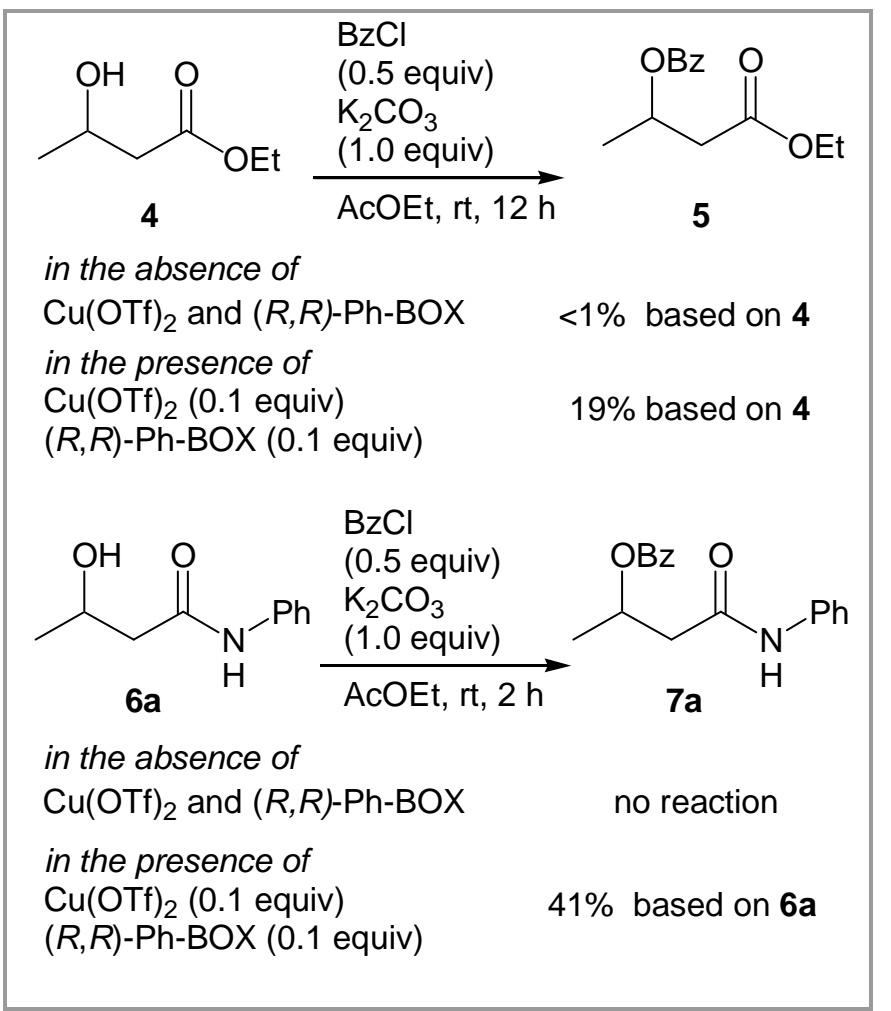

Scheme 2 Benzoylation of ester $\mathbf{4}$ and amide $\mathbf{6 a}$ in the absence or presence of $\mathrm{Cu}(\mathrm{OTf})_{2}$ and $(R, R)-\mathrm{Ph}-\mathrm{BOX}$

Next, we tried competitive reaction between 6a and 2,4pentanediol (8) (syn:anti $\approx 50: 50)$ with or without $\mathrm{Cu}(\mathrm{II})-(R, R)-\mathrm{Ph}-\mathrm{BOX}$ (Scheme 3$)$. In the presence of $\mathrm{Cu}(\mathrm{II})-(R, R)-\mathrm{Ph}-\mathrm{BOX}$ or $\mathrm{Cu}(\mathrm{II})$-racemic-Ph-BOX 7a was exclusively formed, whereas in the absence of $\mathrm{Cu}(\mathrm{II})-(R, R)-\mathrm{Ph}-\mathrm{BOX}$ only monobenzoylated diol 9 (syn:anti $\approx 63: 37$ ) was generated. From these results, we deduced that $\mathbf{6 a}$ is preferentially recognized over $\mathbf{8}$ by 
the copper catalyst. ${ }^{6}$ Acceleration for benzoylaiton of $\mathbf{6 a}$ $(R, R)$ - (or racemic-) Ph-BOX.

was also observed in the presence of $\mathrm{Cu}(\mathrm{OTf})_{2}$ without

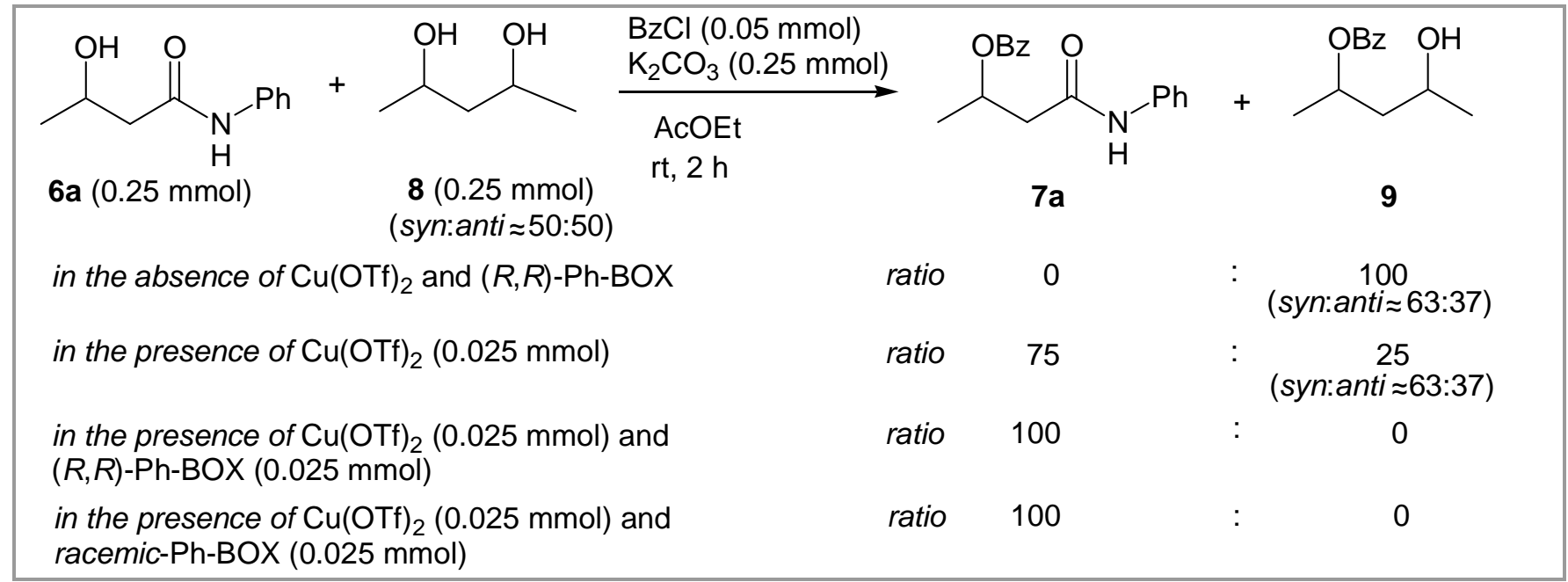

Scheme 3 Competitive reaction between $\mathbf{6 a}$ and $\mathbf{8}$ by benzoylation in the absence or presence of $\mathrm{Cu}(\mathrm{OTf})_{2}$ and $(R, R)-($ or racemic-) $\mathrm{Ph}-\mathrm{BOX}$

In our quest to get excellent reaction conditions for kinetic resolution of DL-6a, we investigated the effect of bases and solvents on benzoylation. ${ }^{7}$ These results are summarized in Table 1. They show a dependence of yield and \% ee of the product $7 \mathbf{a}$ as well as the reaction time on the solvents and bases used. Use of AcOEt as a solvent and $\mathrm{K}_{2} \mathrm{CO}_{3}$ as a base gave $(S)-7 a^{8}$ in $41 \%$ yield and a high enantioselectivity ( $85 \%$ ee) with a selectivity $s$ value $^{10}$ of 27 for 2 h (Entry 1). THF and 1,4-dioxane gave comparable results to AcOEt (Entries 2 and 3), while $\mathrm{CH}_{2} \mathrm{Cl}_{2}$ and $\mathrm{Et}_{2} \mathrm{O}$ were less efficient (Entries 4 and 5). Moreover, use of alcohols such as $\mathrm{iPrOH}$ or EtOH gave $(S)-7 a$ in high enantioselectivity (Entries 6 and 7$). \mathrm{K}_{2} \mathrm{CO}_{3}$ was the most effective base (Entry 1) among the tested bases (Entries 8-11). Use of 0.05 equiv of $\mathrm{Cu}(\mathrm{OTf})_{2}$ and $(R, R)-\mathrm{Ph}-\mathrm{BOX}$ led to slightly inferior result compared to using 0.1 equiv of chiral $\mathrm{Cu}(\mathrm{II})$ catalyst (Entry 12 ).

Table 1 Kinetic Resolution of DL-3-hydroxy- $N$-phenylbutanamide (DL-6a) ${ }^{\mathrm{a}}$

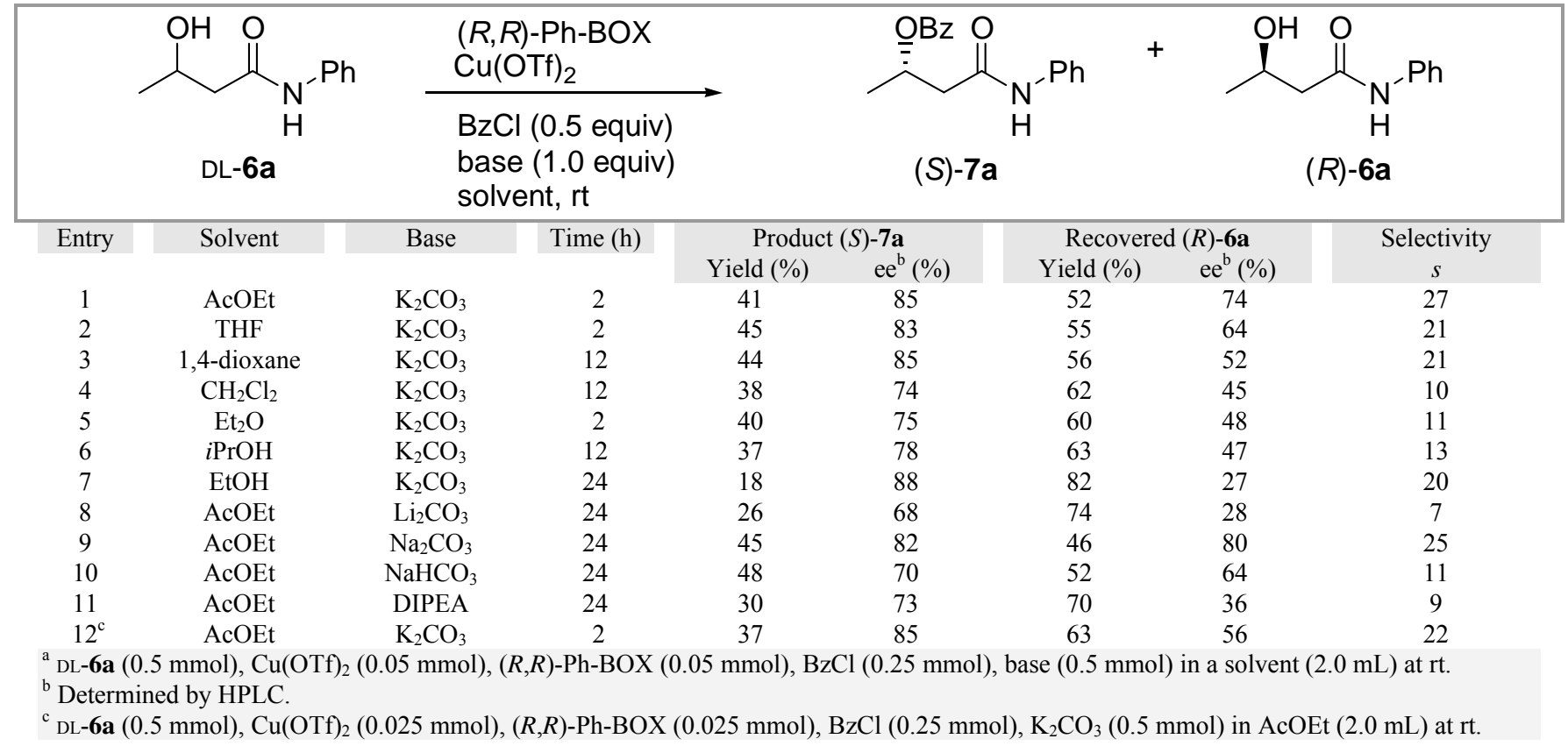

Utilizing the conditions optimized in Table 1, we screened the effect of amide $N$-substituents shown in Table 2. The $s$ value of $N$-4-chlorophenyl amide $\mathbf{6 b}$ was slightly lower than that of $\mathbf{6 a}$ (Entry 1), while $N$-4methylphenyl amide 6c gave high $s$ value of 34 (Entry
2). Benzoylation of $N$-3,5-dimethylphenyl amide $\mathbf{6 d}$ and the corresponding hexafluorinated amide $6 \mathbf{e}$ required longer reaction time, and the $s$ values were moderate for $\mathbf{6 d}$ and poor for $\mathbf{6 e}$ (Entries 3 and 4). N-2Methylphenyl amide $\mathbf{6 f}$ was smoothly asymmetrically 
benzoylated to afford $7 f$ with $89 \%$ ee. $N$-Benzyl amide 6g was inferior to $\mathrm{N}$-phenyl amide 6a (Entry 6). $\mathrm{N}, \mathrm{N}$ -
Disubstituted amides $\mathbf{6 h}, \mathbf{6 i}$ and $\mathbf{6 j}$ also gave slightly lower $s$ values compared to that of $\mathbf{6 a}$ (Entries 7-9).

Table 2 Kinetic resolution of DL-3-hydroxybutanamide derivatives (DL-6b-j) ${ }^{\mathrm{a}}$

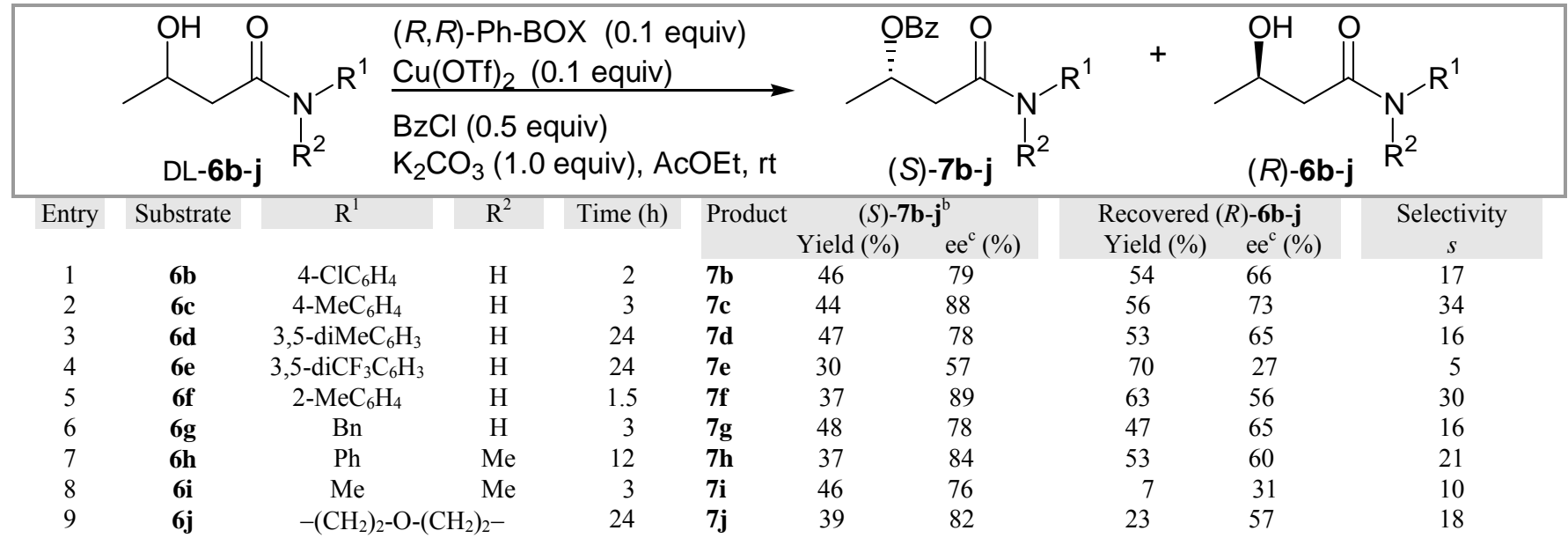

${ }^{\mathrm{a}} \mathrm{DL}-6 \mathbf{b}-\mathbf{j}(0.5 \mathrm{mmol}), \mathrm{Cu}(\mathrm{OTf})_{2}(0.05 \mathrm{mmol}),(R, R)-\mathrm{Ph}-\mathrm{BOX}(0.05 \mathrm{mmol}), \mathrm{BzCl}(0.25 \mathrm{mmol}), \mathrm{K}_{2} \mathrm{CO}_{3}(0.5 \mathrm{mmol})$ in $\mathrm{AcOEt}(2.0 \mathrm{~mL})$ at $\mathrm{rt}$.

${ }^{\mathrm{b}}$ Absolute stereoconfigurations of $\mathbf{7 b} \mathbf{b}-\mathbf{j}$ were deduced on the basis of that of $(S)-7 \mathbf{a}$.

${ }^{\mathrm{c}}$ Determined by HPLC.

Table 3 summarizes kinetic resolution of various 3hydroxyalkanamides 6ap-aw by benzoylation under the optimized reaction condition. Compounds 6ap substituted with Et and 6aq with $n \operatorname{Pr}$ group were asymmetrically benzoylated to afford corresponding optically active (S)-7ap ${ }^{11}$ and (S)-7aq ${ }^{11}$ in good yield and moderate enantioselectivity, respectively (Entries 1 and 2). Although compounds 6ar and 6as substituted with $i \operatorname{Pr}$ tioselectivity, the yield was low (Entries 3 and 4). Benzoylation of cyclohexylated compound 6at did not proceed (Entry 5), while phenylated 6au was benzoylated to afford $(R)-7 \mathbf{a u}^{12}$ in moderate yield and good enantioselectivity (Entry 6). Straight carbon-chained compounds $6 \mathbf{a v}$ terminally fuctionalized with $\mathrm{Br}$ atom and 6aw with $N$-Boc protected amino group gave good $s$ value of 16 and 18, respectively (Entries 7 and 8). and $i \mathrm{Bu}$ were kinetically resolved with moderate enan-

Table 3 Kinetic resolution of various DL-3-hydroxyalkanamides (DL-6ap-aw) ${ }^{\mathrm{a}}$

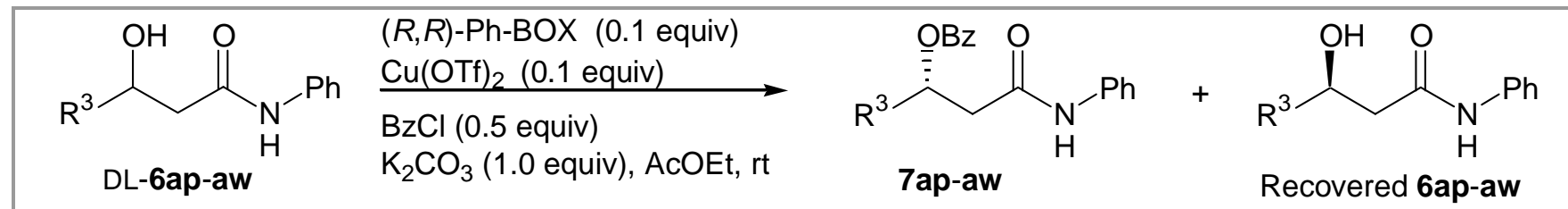

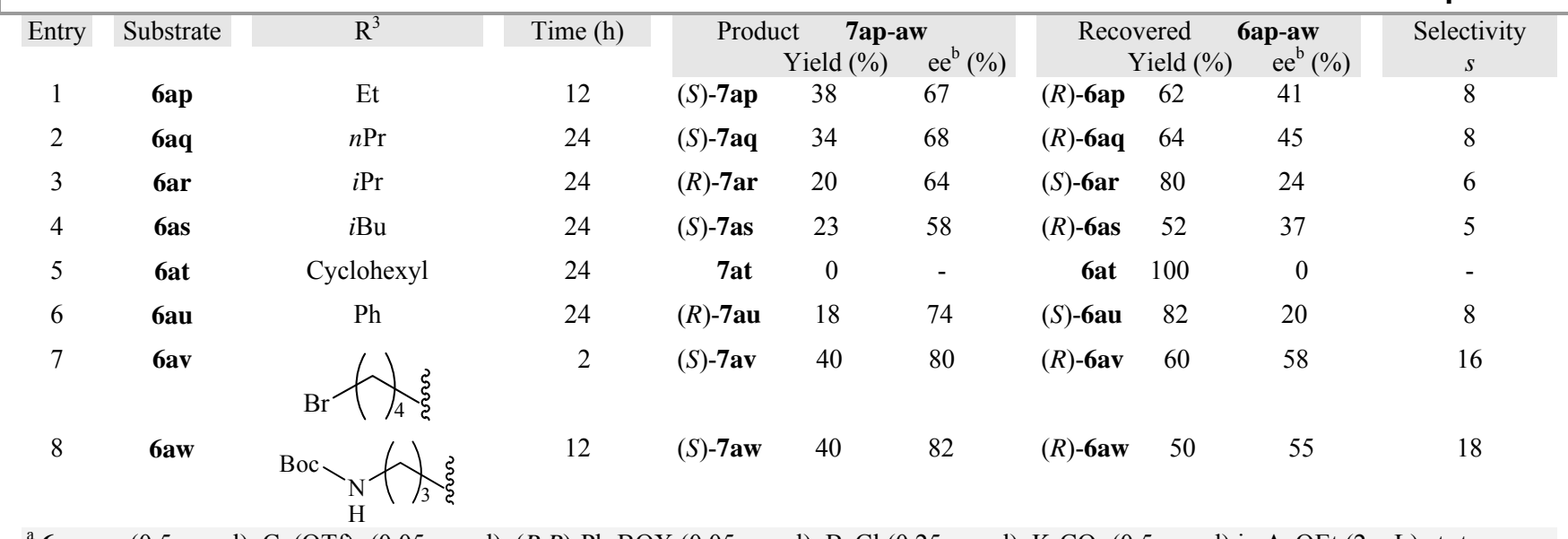

\footnotetext{
${ }^{\mathrm{a}}$ 6ap-aw $(0.5 \mathrm{mmol}), \mathrm{Cu}(\mathrm{OTf})_{2}(0.05 \mathrm{mmol}),(R, R)-\mathrm{Ph}-\mathrm{BOX}(0.05 \mathrm{mmol}), \mathrm{BzCl}(0.25 \mathrm{mmol}), \mathrm{K}_{2} \mathrm{CO}_{3}(0.5 \mathrm{mmol})$ in $\mathrm{AcOEt}(2 \mathrm{~mL})$ at rt. ${ }^{\mathrm{b}}$ Determined by HPLC.
}

To increase the scope of our reaction, we tried enantioselective benzoylation and tosylation $^{13}$ of 2,2bis(hydroxymethyl)alkanamides 10a-c. The results are shown in Table 4. Asymmetric benzoylation and tosyla-

tion of 10a-c smoothly proceeded to give the corresponding mono-benzoylated compounds $11 \mathbf{a}-\mathbf{c}^{14}$ and mono-tosylated compounds $12 \mathbf{a}-\mathbf{c}^{14}$ with good to high yields and enantioselectivities (Entries 1-6). It is note- 
worthy to state that 12a-c were obtained in higher enantiomeric purity than those of 11a-c (Entries 4-6), partially due to an intramolecular acyl transfer ${ }^{15}$ which caused racemization of optically pure benzoylated compound 11c, but did not happen in the case of tosylation. This is illustrated in Scheme 4.

Table 4 Asymmetric benzoylation and tosylation of prochiral 10a-c $\mathbf{c}^{\mathrm{a}}$

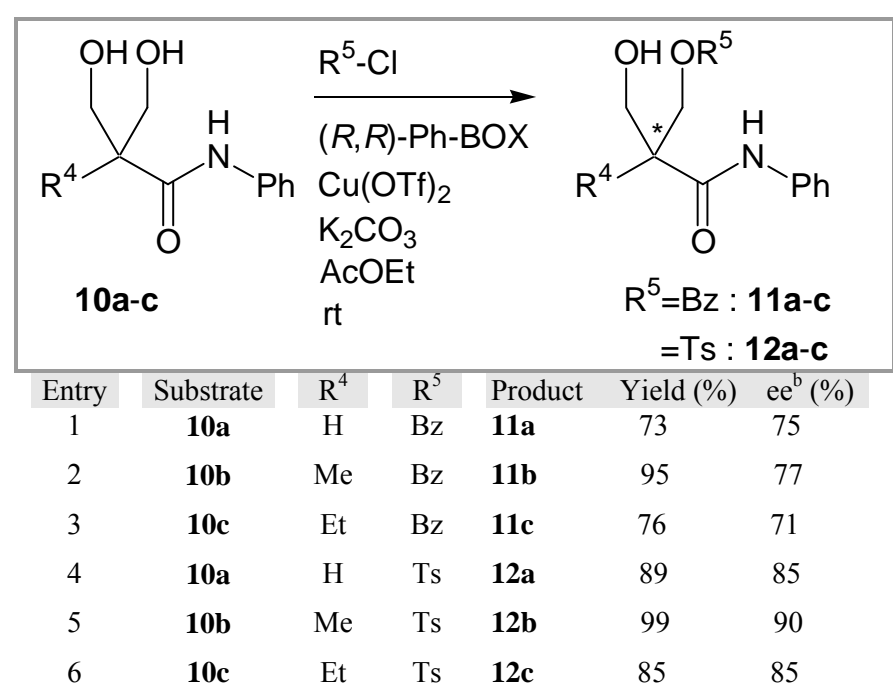

${ }^{\mathrm{a}}$ 10a-c $(0.5 \mathrm{mmol}), \mathrm{Cu}(\mathrm{OTf})_{2}(0.05 \mathrm{mmol}),(R, R)-\mathrm{Ph}-\mathrm{BOX}(0.05$ $\mathrm{mmol}), \mathrm{R}^{5}-\mathrm{Cl}(0.5 \mathrm{mmol}), \mathrm{K}_{2} \mathrm{CO}_{3}(0.75 \mathrm{mmol})$ in $\mathrm{AcOEt}(2 \mathrm{~mL})$ at $\mathrm{rt}$ for $4 \mathrm{~h}$ (benzoylation) or $12 \mathrm{~h}$ (tosylation).

${ }^{\mathrm{b}}$ Determined by HPLC.

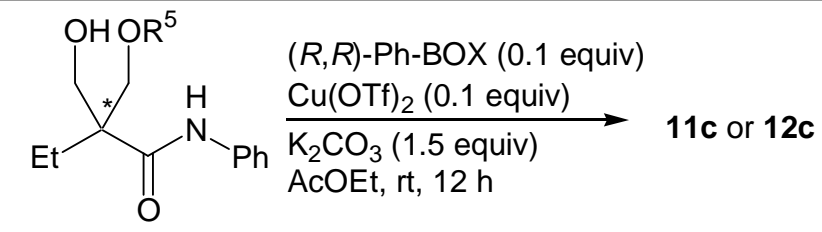

$$
\begin{aligned}
& \mathrm{R}^{5}=\mathrm{Bz}: \mathbf{1 1 c} \text { (71\% ee) } \\
& \mathrm{R}^{5}=\mathrm{Bz}: \text { : 11c (5\% ee) } \\
& \text { =Ts : 12c (85\% ee) } \\
& =\text { Ts : } 12 \mathrm{c}(85 \% \text { ee })
\end{aligned}
$$

Scheme 4 Racemization of 11c and 12c

In summary, we have accomplished the non-enzymatic kinetic resolution of 3-hydroxyalkanamides by benzoylation and desymmetrization of 2,2-bis(hydroxymethyl)alkanamides by tosylation utilizing chiral copper catalyst. The mechanistic study of these reactions and their synthetic applications ${ }^{16}$ are underway.

\section{Acknowledgment}

O.O. and Y.D. are grateful for a Grant-in-Aid for Scientific Research (C) (19550109) from Japan Society for the Promotion of Science and a Grant-in-Aid for Young Scientists (B) (19790017) from the Ministry of Education, Science, Sports and Culture, Japan, respectively.

\section{References}

(1) (a) Berks, A. H. Tetrahedron 1996, 52, 331. (b) Pàmies, O.; Bäckvall, J. -E. Adv. Synth. Catal.
2002, 344, 947. (c) Genet, J. -P. Acc. Chem. Res. 2003, 36, 908. (d) Mlynarski, J. Eur. J. Org. Chem. 2006, 4779.

(2) Recent literatures for kinetic resolution of 3hydroxyalkanoic acid derivatives by enzymatic methods: (a) Xu, C.; Yuan, C. Tetrahedron 2005, 61, 2169. (b) Turcu, M. C.; Kiljunen, E.; Kanerva, L. T. Tetrahedron: Asymmetry 2007, 18, 1682.

(3) Ishihara, K.; Kosugi, Y.; Akakura, M. J. Am. Chem. Soc. 2004, 126, 12212 .

(4) A recent review of chiral bis(oxazoline) ligands: Desimoni, G.; Faita, G.; Jørgensen, K. A. Chem. Rev. 2006, 106, 3561.

(5) Mono-benzoylation: (a) Matsumura, Y.; Maki, T.; Murakami, S.; Onomura. O. J. Am. Chem. Soc. 2003, 125, 2052. Mono-carbamoylation: (b) Matsumoto, K.; Mitsuda, M.; Ushijima, N.; Demizu, Y.; Onomura. O.; Matsumura, Y. Tetrahedron Lett. 2006, 47, 8453. Mono-oxidation of 1,2-diols: (c) Onomura, O.; Arimoto, H.; Matsumura, Y.; Demizu, Y. Tetrahedron Lett. 2007, 48, 8668. Benzoylation of vic-aminoalcohols: (d) Mitsuda, M.; Tanaka, T.; Tanaka, T.; Demizu, Y.; Onomura, O.; Matsumura, Y. Tetrahedron Lett. 2006, 47, 8073. Review: (e) Matsumura, Y.; Onomura, O.; Demizu, Y. Yuki Gosei Kagaku Kyokaishi 2007, 65, 216.

(6) Representative literatures for non-enzymatic asymmetric desymmetrization of 1,3-diols: Monocarbamoylation; (a) Otera, J.; Sakamoto, K.; Tsukamoto, T.; Orita, A. Tetrahedron Lett. 1998, 39, 3201. Mono-benzoylation: (b) Oriyama, T.; Taguchi, H.; Terakado, D.; Sano, T. Chem. Lett. 2002, 26. (c) Trost, B. M.; Mino. T. J. Am. Chem. Soc. 2003, 125, 2410. (d) Mizuta, S.; Tsuzuki, T.; Fujimoto, T.; Yamamoto, Y. Org. Lett. 2005, 7, 3633. Mono-acetylation of 2-amino-1,3-diols: (e) Honjo, T.; Nakano, M.; Sano, S.; Shiro, M.; Yamaguchi, K.; Sei, Y.; Nagao, Y. Org. Lett. 2007, 9, 509.

(7) Typical procedure for kinetic resolution: Into a solution of $\mathrm{Cu}(\mathrm{OTf})_{2}(0.05 \mathrm{mmol}, 18.1 \mathrm{mg})$ and $(R, R)$-Ph-BOX $(0.05 \mathrm{mmol}, 16.7 \mathrm{mg})$ in AcOEt $(2$ $\mathrm{mL})$ were added DL-6a $(0.5 \mathrm{mmol}, 89.6 \mathrm{mg})$, $\mathrm{K}_{2} \mathrm{CO}_{3}(0.5 \mathrm{mmol}, 69.1 \mathrm{mg})$ and benzoyl chloride $(0.25 \mathrm{mmol}, 0.029 \mathrm{~mL})$. After stirring for $2 \mathrm{~h}$ at $\mathrm{rt}$, to the reaction mixture water $(10 \mathrm{~mL})$ was added. The organic portion was extracted with AcOEt (20 $\mathrm{mL} \times 3$ ). The combined organic layer was dried over $\mathrm{MgSO}_{4}$ and solvent removed in vacuo. The residue was chromatographed on $\mathrm{SiO}_{2}$ (n-hexane : $\mathrm{AcOEt}=3: 1)$ to afford $(S)-7 \mathbf{a}(58.1 \mathrm{mg}, 41 \%$ yield, $85 \%$ ee) as a white solid. M.p. $98-99{ }^{\circ} \mathrm{C}$. $[\alpha]^{23}{ }_{\mathrm{D}}+55.4\left(\right.$ c $\left.1.0, \mathrm{CHCl}_{3}\right) .{ }^{1} \mathrm{H}$ NMR $(300 \mathrm{MHz}$, $\left.\mathrm{CDCl}_{3}\right) \delta 8.03(\mathrm{~d}, J=7.2 \mathrm{~Hz}, 1 \mathrm{H}), 7.78($ br s, $1 \mathrm{H})$, $7.56(\mathrm{t}, J=9.0 \mathrm{~Hz}, 1 \mathrm{H}), 7.51-7.38(\mathrm{~m}, 4 \mathrm{H}), 7.29(\mathrm{t}$, $J=9.0 \mathrm{~Hz}, 3 \mathrm{H}), 7.09(\mathrm{t}, J=9.0 \mathrm{~Hz}, 1 \mathrm{H}), 5.63-5.50$ $(\mathrm{m}, 1 \mathrm{H}), 2.85(\mathrm{dd}, J=6.3,14.4 \mathrm{~Hz}, 1 \mathrm{H}), 2.68(\mathrm{dd}$, $J=6.3,14.4 \mathrm{~Hz}, 1 \mathrm{H}), 1.51(\mathrm{~d}, J=6.3 \mathrm{~Hz}, 3 \mathrm{H})$. Optical purity of product $(S)-7$ a was determined by chiral HPLC: Dicel Chiralcel OD-H column $(4.6 \mathrm{~mm} \phi, 250 \mathrm{~mm}), n$-hexane : isopropanol $=10$ : 1, wavelength: $220 \mathrm{~nm}$, flow rate: $1.0 \mathrm{~mL} / \mathrm{min}$, retention time: $20.0 \mathrm{~min}((R)-7 \mathbf{a}), 22.5 \mathrm{~min}((S)-7 \mathbf{a})$.

(8) The absolute stereoconfiguration of recovered $(R)$ 6a was determined by comparing with specific rotation of authentic sample. Compound $(R)-6 a$ (74\% ee): $[\alpha]^{22}-28.6\left(c\right.$ 1.1, $\left.\mathrm{CHCl}_{3}\right)$. [lit. ${ }^{9}(R)-6 \mathbf{a}$ $\left.[\alpha]^{20}{ }_{\mathrm{D}}^{-37}\left(\mathrm{c} 1.0, \mathrm{CHCl}_{3}\right)\right]$. 
(9) Gendre, P. L.; Offenvecher, M.; Bruneau, C.; Dixneuf, P. H. Tetrahedron: Asymmetry 1998, 9, 2279.

(10) The selectivity factor $s$ was determined using the equation $s=k_{\text {rel (fast/slow })}=\ln \left[(1-C)\left(1-e_{\mathrm{A}}\right)\right] / \ln [(1-$ $\left.C)\left(1+\mathrm{ee}_{\mathrm{A}}\right)\right]$, where $C=\mathrm{ee}_{\mathrm{A}} /\left(\mathrm{ee}_{\mathrm{A}}+\mathrm{ee}_{\mathrm{B}}\right), \mathrm{ee}_{\mathrm{A}}=$ ee of recovered starting material, $e_{\mathrm{B}}=$ ee of product. Kagan, H. B.; Fiaud, J. C. Topics in Stereochemistry; Eliel, E. L., Ed.; Wiley \& Sons: New York, 1988, Vol. 18, 249-330.

(11) Absolute stereoconfigurations of 7ap-at,av,aw shown in Table 3 were deduced on the basis of those of $(S)$-7a and $(R)-7$ au.

(12) The absolute stereoconfiguration of $(R)$-7au was determined by comparing with that of authentic $(S)-7 a u$, which was prepared from commercially available (S)-(-)-3-hydroxy-3-phenylpropionitrile: Dicel Chiralcel OD-H column (4.6 mm $\phi, 250 \mathrm{~mm})$, $n$-hexane : isopropanol $=10: 1$, wavelength: 220 $\mathrm{nm}$, flow rate: $1.0 \mathrm{~mL} / \mathrm{min}$, retention time: $36 \mathrm{~min}$ $((R)-7 \mathbf{a u}), 42$ min $((S)-7 \mathbf{a u}) .(R)-7 \mathbf{a u}(74 \%$ ee): $[\alpha]_{\mathrm{D}}^{25}-13.8$ (c 1.0, $\mathrm{CHCl}_{3}$ ).

(13) Kinetic resolution of DL-6a with $p$-TsCl gave $(S)$ tosylated product with somewhat lower yield $(36 \%)$ and enantioselectivity $(67 \%$ ee) than those of benzoylation.

(14) Specific rotations, 11a: $[\alpha]^{28}{ }_{\mathrm{D}}-16.4$ (c 1.0, $\left.\mathrm{CHCl}_{3}\right)$. 11b: $[\alpha]_{\mathrm{D}}^{28}+6.9\left(\mathrm{c} 1.0, \mathrm{CHCl}_{3}\right)$. 11c: $\left.[\alpha]_{\mathrm{D}}^{28}+0.6(c) 1.0, \mathrm{CHCl}_{3}\right) \cdot 12 \mathrm{a}:[\alpha]_{\mathrm{D}}^{24}+15.2(c$ $\left.0.95, \mathrm{CHCl}_{3}\right)$. 12b: $[\alpha]^{24}-21.8\left(c 1.0, \mathrm{CHCl}_{3}\right)$. 12c: $[\alpha]_{\mathrm{D}}^{26}-43.2$ ( c $\left.1.0, \mathrm{CHCl}_{3}\right)$.

(15) Edin, M.; Martín-Matute, B.; Bäckvall J.-E. Tetrahedron: Asymmetry 2006, 17, 708.

(16) Mesylation of $(R)-6 a$ followed by cyclization under basic conditions gave the corresponding optically active $\beta$-lactam with complete stereoinversion.

(17) Sakaki, J.; Kobayashi, S.; Sato, M.; Kaneko, C. Chem. Pharm. Bull. 1989, 37, 2952. 
